University of Nebraska - Lincoln

DigitalCommons@University of Nebraska - Lincoln

Uniformed Services University of the Health

Sciences

U.S. Department of Defense

2002

\title{
Derivation of risk based wipe surface screening levels for industrial scenarios
}

\author{
Lisa M. May \\ Uniformed Services University of the Health Sciences \\ Bonnie Gaborek \\ US Army Center for Health Promotion Preventive Medicine \\ Tony Pitrat \\ US Army Center for Health Promotion Preventive Medicine \\ Laura Peters \\ US Army Center for Health Promotion Preventive Medicine
}

Follow this and additional works at: https://digitalcommons.unl.edu/usuhs

Part of the Medicine and Health Sciences Commons

\begin{abstract}
May, Lisa M.; Gaborek, Bonnie; Pitrat, Tony; and Peters, Laura, "Derivation of risk based wipe surface screening levels for industrial scenarios" (2002). Uniformed Services University of the Health Sciences. 7. https://digitalcommons.unl.edu/usuhs/7
\end{abstract}

This Article is brought to you for free and open access by the U.S. Department of Defense at DigitalCommons@University of Nebraska - Lincoln. It has been accepted for inclusion in Uniformed Services University of the Health Sciences by an authorized administrator of DigitalCommons@University of Nebraska Lincoln. 


\title{
Derivation of risk based wipe surface screening levels for industrial scenarios
}

\author{
Lisa M. May,*, Bonnie Gaborek ${ }^{\mathrm{b}}$, Tony Pitrat ${ }^{\mathrm{b}}$, Laura Peters ${ }^{\mathrm{b}}$ \\ ${ }^{a}$ Uniformed Services University of the Health Sciences, Department of Preventive Medicine and Biometrics, \\ 4301 Jones Bridge Road, Room A-1044, Bethesda, MD 20814-4799, USA \\ ${ }^{\mathrm{b}}$ US Army Center for Health Promotion Preventive Medicine, Environmental Health Risk Assessment Program, \\ 5158 Blackhawk Road, Building E-1675, Room 108, Aberdeen Proving Ground, Maryland 21010-5403, USA
}

Received 1 June 2001; accepted 10 September 2001

\begin{abstract}
The environmental characterization of building interiors and other surfaces has generally been performed with wipe-sampling because it is a non-destructive technique. There is no consensus, however, as to the interpretation of the results of wipe-sampling. Specifically, there is not a standardized method to determine if chemicals found at sampled levels pose a threat to human health. A methodology was developed, based on acceptable health risk levels, to derive screening levels for evaluating wipe-sampling results pertaining to industrial scenarios. The methodology was based on the United States Environmental Protection Agency (USEPA) Region IX Preliminary Remediation Goal (PRG) approach; a multi-exposure methodology commonly used for evaluating soil concentrations. PRGs are the USEPA determined health based goals for soil preliminary remediation efforts. Probabilistic techniques were used to conduct a sensitivity analysis of the methodology to determine which variables drive the ultimate screening levels. Discrete values were then selected based on standard industrial scenarios common to the US Army. The wipe surface screening levels reported are for use as preliminary guidelines which help to determine whether further sampling or cleanup are necessary. The levels are not meant as cleanup or compliance criteria. (c) 2002 Elsevier Science B.V. All rights reserved.
\end{abstract}

Keywords: Wipe-sampling; Surfaces; Risk assessment; Dermal exposure; Dermal contact; Screening levels; Health risk; Risk levels; PRG; Industrial screening levels; Construction screening levels; Multi-exposure; Chemical exposure; Chemical risk assessment; Contact hazards; Probabilistic risk assessment; Sensitivity analysis; Monte Carlo simulation; Uncertainty analysis; Explosives; Nitroglycerin; RDX; HMX

\section{Introduction}

Currently, no single accepted standardized approach for evaluating wipe sampling data from potentially contaminated smooth surfaces exists.

\footnotetext{
*Corresponding author. Tel.: +1-410-436-5205; fax: $+1-$ 436-8170.

E-mail address: lmay@usuhs.mil (L.M. May).
}

Dermal contact risk is becoming an issue due to an increase in site closures and site clean-up efforts of buildings where internal surfaces may be contaminated with hazardous substances. Therefore, we have developed a method using simulation to estimate industrial wipe surface screening levels. This method applies a screening approach to assess health risks through the ingestion, inhalation, and/ 
or dermal absorption of substances contained in the dust and measured by wipe samples from potentially contaminated non-porous surfaces. The underlying assumptions of this method are that the substances are contained in soil dust; that wipe sampling is capable of any level of detection; and that wipe sampling measures $100 \%$ of the substances found on the non-porous surfaces. The limitations of this method stem from the lack of toxicity values for dermal absorption and the lack of accurate, discrete dermal exposure values.

At the onset of this project, USACHPPM created a multi-disciplinary team to evaluate the current wipe sampling methodology and to interpret literature. Wipe sampling is a surface sampling method where $100 \mathrm{~cm}^{2}$ of a surface is wiped with a filter and analyzed for environmental chemicals. USACHPPM chose the USEPA Region III wipe sample guidance (USEPA 1997a) and incorporated some of the USEPA Region IX guidance (USEPA 1999) as a starting point for our method. The environmental contaminants of concern were explosives (HMX, RDX, Nitroglycerin). HMX is an acronym for High Melting eXplosive. It is also known as octogen and cyclotetramethylene-tetranitramine, as well as by other names. It is a colorless solid that dissolves slightly in water. Only a small amount of HMX will evaporate into the air; however, it can occur in air attached to suspended particles or dust. The taste and smell of HMX are not known. RDX stands for Royal Demolition eXplosive. It is also known as cyclonite or hexogen. The chemical name for RDX is 1,3,5-trinitro1,3,5-triazine. It is a white powder and is very explosive. RDX is used as an explosive and is also used in combination with other ingredients in explosives. Its odor and taste are unknown. It is a synthetic product that does not occur naturally in the environment. It creates fumes when it is burned with other substances.

The exposure scenarios evaluated by this method were construction or demolition workers who are remodeling or demolishing a facility and a general industrial worker entering facilities no longer in use to retrieve something or to complete some basic building maintenance. These scenarios are assumed to take place after the facilities have been scabbled. Both scenarios involve dermal con- tact with dust deposited on non-porous surfaces during the demilitarization process, and the resulting exposures from the dermal contact (inhalation, ingestion and dermal absorption). The screening methodology described in this report only applies to the characterization of the interior surfaces of a previously used industrial building or room at the site that is transferred for construction/demolition or general industrial use.

These screening levels are best used where the actual exposure is similar to the exposure assumptions used in the methodology (e.g. there is a continuing source of contamination or there is more frequent surface contact). The methodology presented in this document is to be used as a limited baseline screening tool, and should not be used in place of the judgment of a competent health and safety professional, or in place of regulatory guidance. But rather, the methodology is provided as a mechanism to generically screen for key indicators of human health risk in specific industrial scenarios. Most of the site-specific assumptions were made using the USEPA default values (USEPA, 1997b). The source of some sitespecific assumptions was the professional judgment of the USACHPPM Health Risk Assessment Program staff.

The Table 1 outlines the results of the screening level methodology for three specific explosive compounds (HMX, RDX, Nitroglycerin) as applied to the site construction and industrial scenarios. This paper summarizes the methodology employed in determining wipe surface screening levels and addresses site-specific conditions, as well as uncertainties associated with variable selection.

\section{Methods}

Current Risk Assessment Guidance for Superfund (RAGS) equations were modified for dermal contact as the main exposure route to create screening levels (USEPA, 1989). Appropriate toxicity, exposure scenario, and exposure pathway analysis were conducted as a first step to the risk assessment. Table 2 summarizes, with references, the exposure ranges and discrete values for the variables used in the adjusted RAGS equations. 
Table 1

Health based wipe surface screening levels

\begin{tabular}{lllll}
\hline Substance & $\begin{array}{l}\text { Exposure } \\
\text { scenario }\end{array}$ & $\begin{array}{l}\text { Non-cancer } \\
\text { value } \\
\left(\mu \mathrm{g} / 100 \mathrm{~cm}^{2}\right)\end{array}$ & $\begin{array}{l}\text { Cancer } \\
\text { value } \\
\left(\mu \mathrm{g} / 100 \mathrm{~cm}^{2}\right)\end{array}$ & $\begin{array}{l}\text { Screening } \\
\text { value } \\
\left(\mu \mathrm{g} / 100 \mathrm{~cm}^{2}\right)\end{array}$ \\
\hline HMX & Industrial & $1.7 \mathrm{E}+05$ & & $1.7 \mathrm{E}+05$ \\
& Construction & $2.3 \mathrm{E}+03$ & $2.3 \mathrm{E}+03$ \\
RDX & Industrial & $1.0 \mathrm{E}+04$ & $8.5 \mathrm{E}+01$ & $8.5 \mathrm{E}+01$ \\
Nitroglycerin & Construction & $1.4 \mathrm{E}+02$ & $2.9 \mathrm{E}+01$ & $6.6 \mathrm{E}+01$ \\
& Industrial & & $6.6 \mathrm{E}+02$ & $2.3 \mathrm{E}+02$ \\
\hline
\end{tabular}

${ }^{\text {a }}$ Cancer summary values are based upon risks of 1 in 1000000 (1E-06)

Screening level calculations are very sensitive to assumptions made concerning input variables. Therefore, simulation was used to randomly model 10000 different scenarios to determine which variables must be further researched. Deterministic exposure variable values were selected using Monte Carlo simulation and sensitivity analysis and through further research and determination of sitespecific conditions. Most of the exposure parameters used in this method are variable and thus, have a range of values that can be expected in each exposure scenario. In some instances, a specific point value can be estimated for the exposure parameter but in most instances, a range of values can be expected. Therefore, the range of possible values is published in Table 2 . The following discussion describes the source of the range of values expected for each variable and the variable definitions.

1. Dermal Surface Area Available for Absorption. Dermal surface area available for absorption is the amount of skin area that could come in contact with a contaminated surface. The range of possible values for Dermal Surface Area Available for Absorption was gathered from the USEPA Exposure Factors Handbook (USEPA, 1997b). This value can vary from the mean value for the surface area of the hands to the mean value for total upper extremity surface area. Upper extremities, including the upper arms, forearms and hands, are assumed to be the most conservative value for the surfaces likely to be exposed in an industrial setting. The value for males was used because it is larger than that of females and, therefore, provides a conservative estimate (USEPA, 1997b). For the construction/ demolition and industrial worker scenarios, the value used was the total surface area of the hands and forearms of an adult male, 0.198 $\mathrm{m}^{2}$ (USEPA, 1997b).

2. Fraction of Available Dermal Area that Contacts the Surface. The fraction of available dermal area that contacts the surface is the percentage of dermal surface area available for absorption expected to come in contact with a contaminated surface each day. Values for the Fraction of Available Dermal Area that Contacts the Surface ranged from 0.16 (one contact with palm of hand against a flat, smooth, hard surface) to 0.39 ( 2 contacts with palm of hand against a flat, smooth, hard surface) (Brouwer, 1999). It has been noted that a larger fraction should be assumed for a more flexible surface. The New York Department of Health (NYDH) conducted a risk assessment to establish minimum safe Polychlorinated Biphenyl (PCB) residue levels for re-entry after a PCB fire. They used a value of $25 \%$ to represent the amount of available dermal area contacted (NYDEH, 1985). Additionally, USEPA Region III has stated that values of $50 \%$ were used, but that $10 \%$ may be appropriate (USEPA, 1997a). For these scenarios, values of $25 \%$ were selected.

3. Dermal Surface Area Available for Ingestion. The dermal surface area available for ingestion is the amount of skin area that could come in 
Summary of general exposure value ranges used in industrial screening levels

\begin{tabular}{|c|c|c|c|c|c|c|}
\hline Variable & & $\begin{array}{l}\text { Construction/ } \\
\text { demolition } \\
\text { worker }\end{array}$ & $\begin{array}{l}\text { General } \\
\text { industrial } \\
\text { worker }\end{array}$ & $\begin{array}{l}\text { Construction } \\
\text { demolition } \\
\text { worker }\end{array}$ & $\begin{array}{l}\text { General } \\
\text { industrial } \\
\text { worker }\end{array}$ & Reference \\
\hline $\begin{array}{l}\text { Dermal surface } \\
\text { area available } \\
\text { for absorption }\end{array}$ & $\begin{array}{l}S A_{d} \\
\left(\mathrm{~m}^{2}\right)\end{array}$ & $0.084-0.319$ & $0.084-0.319$ & 0.198 & 0.198 & USEPA 1997b \\
\hline $\begin{array}{l}\text { Fraction of } \\
\text { available dermal } \\
\text { area that contacts } \\
\text { the surface }\end{array}$ & $F_{d}$ & $0.16-0.39$ & $0.16-0.39$ & 0.25 & 0.25 & $\begin{array}{l}\text { NYDEP } 1985 \\
\text { USEPA } 1997 \mathrm{a}\end{array}$ \\
\hline $\begin{array}{l}\text { Dermal surface } \\
\text { area available } \\
\text { for ingestion }\end{array}$ & $S A_{g}\left(\mathrm{~m}^{2}\right)$ & $0.084-0.319$ & $0.084-0.319$ & 0.084 & 0.084 & USEPA 1997a \\
\hline $\begin{array}{l}\text { Fraction of } \\
\text { available dermal } \\
\text { area that contacts } \\
\text { mouth }\end{array}$ & $F_{g}$ & $0-1.0$ & $0-1.0$ & 0.1 & 0.1 & USEPA 1997a \\
\hline $\begin{array}{l}\text { Contact frequency } \\
\text { with surface } \\
\text { (events per day) }\end{array}$ & $E V\left(\mathrm{~d}^{-1}\right)$ & $0-24$ & $0-24$ & 12 & 3 & USEPA $1997 a^{c}$ \\
\hline $\begin{array}{l}\text { Fraction of dust } \\
\text { transferred from } \\
\text { surface to skin }\end{array}$ & $F T \_s s$ & $0-1.0$ & $0-1.0$ & 0.1 & 0.1 & USEPA 1997a \\
\hline $\begin{array}{l}\text { Fraction of dust } \\
\text { transferred from } \\
\text { skin to mouth }\end{array}$ & $F T \_f t m$ & $0-1.0$ & $0-1.0$ & 0.5 & 0.3 & $\begin{array}{l}\text { Schneider } \\
1993\end{array}$ \\
\hline $\begin{array}{l}\text { Hand to mouth } \\
\text { events }\end{array}$ & HTME & $0-24$ & $0-24$ & 3 & 3 & USEPA 1997a \\
\hline Inhalation rate & $I R_{i}\left(\mathrm{~m}^{3} / \mathrm{d}\right)$ & 15, S.D. $=6^{\mathrm{d}}$ & 12, S.D. $=5^{\mathrm{d}}$ & 20 & 15 & USEPA $1997 b$ \\
\hline $\begin{array}{l}\text { Resuspension } \\
\text { factor }\end{array}$ & $K\left(\mathrm{~m}^{-1}\right)$ & $1 \mathrm{E}-05-2 \mathrm{E}-04$ & 1E-08-1E-07 & $1 \mathrm{E}-04$ & $5 \mathrm{E}-08$ & Sansone 1987 \\
\hline $\begin{array}{l}\text { Dermal absorption } \\
\text { efficiency }\end{array}$ & $D A F$ & $0.01-0.1$ & $0.01-0.1$ & 0.1 & 0.1 & USEPA 1998, 1999 \\
\hline $\begin{array}{l}\text { Exposure } \\
\text { frequency }^{\mathrm{a}}\end{array}$ & $E F(\mathrm{~d} /$ year $)$ & Site-specific & Site-specific & 250 & 21 & USEPA $1997 b$ \\
\hline $\begin{array}{l}\text { Exposure } \\
\text { duration }^{\mathrm{a}}\end{array}$ & $E D$ (year) & \# years construction & \# work years & 1.0 & 25 & USEPA 1997b \\
\hline Body weight & $B W(\mathrm{~kg})$ & 71.8, S.D. $=14.6^{\mathrm{d}}$ & 71.8, S.D. $=14.6^{\mathrm{d}}$ & 71.8 & 71.8 & USEPA 1997b \\
\hline
\end{tabular}


Table 2 (Continued)

\begin{tabular}{|c|c|c|c|c|c|c|}
\hline Variable & & $\begin{array}{l}\text { Construction/ } \\
\text { demolition } \\
\text { worker }\end{array}$ & $\begin{array}{l}\text { General } \\
\text { industrial } \\
\text { worker }\end{array}$ & $\begin{array}{l}\text { Construction } \\
\text { demolition } \\
\text { worker }\end{array}$ & $\begin{array}{l}\text { General } \\
\text { industrial } \\
\text { worker }\end{array}$ & Reference \\
\hline Averaging Time ${ }^{\mathrm{b}}$ & $A T$ (year) & Exposure duration (non-carci) & Exposure duration (non-carc) & 0.5 (non-carc) & 25 (noncarc) & USEPA $1997 b$ \\
\hline $\begin{array}{l}\text { Averaging } \\
\text { Time }_{\text {lifetime }}\end{array}$ & $\begin{array}{l}A T_{\text {lifetime }} \\
\text { (year) }\end{array}$ & $\begin{array}{l}70 \\
\text { (carcinogens) }\end{array}$ & $\begin{array}{l}70 \\
\text { (carcinogens) }\end{array}$ & $\begin{array}{l}70 \\
\text { (carcinogens) }\end{array}$ & $\begin{array}{l}70 \\
\text { (carcinogens) }\end{array}$ & USEPA $1997 b$ \\
\hline
\end{tabular}

${ }^{a}$ Exposure duration and frequency are site-specific parameters.

${ }^{b}$ For the non-carcinogenic evaluation, averaging time equals the exposure duration.

${ }^{\mathrm{c}}$ Must obtain from site-specific conditions, USEPA, 1997a sites typically equal to 1 per day.

${ }^{\mathrm{d}}$ S.D. $=$ Standard Deviation from the mean value represented. 
contact with a contaminated surface that could possibly be ingested by a person. This value must be adjusted to include the fraction of this surface area that would most likely be ingested. The adjustment variable is the fraction of available dermal area that contacts the mouth (below). As recommended by USEPA Region III, the range of values estimated is the surface area of both hands to the total surface area of the upper extremities as in the dermal surface area available for absorption (USEPA, 1997a). This assumption applies to both the construction/demolition worker and industrial scenarios. This range is a conservative estimate of the amount of substance that could enter the mouth of a worker in these scenarios, because most people will not bring their entire upper extremities to their mouth. For the construction/demolition and industrial scenarios, the value of the total surface area of both hands was used as the dermal surface area available for ingestion, $0.084 \mathrm{~m}^{2}$ (USEPA, 1997b).

4. Fraction of Available Dermal Area that Contacts Mouth. The fraction of available dermal area that contacts the mouth is the percentage of dermal surface area available for ingestion that is expected to come in contact with the mouth. USEPA Region III recommends using the assumption that approximately $10 \%$ of the material on the hand surface (surface area available for ingestion) will be transferred to the mouth (USEPA, 1997a). However, this value could vary from 0 to $100 \%$ of the available surface area transferred to the mouth. For these exposure scenarios, values of $10 \%$ were selected.

5. Contact Frequency With Surface (Events Per Day). The contact frequency with the surface or number of events per day is a measure of the amount of times that the exposed person contacts the contaminated surface. According to USEPA Region IX, this value can vary from 0 to 24 times per day (USEPA, 1999). USEPA Region III recommends using the assumption of 1 contact per day up to the worst case of 24 per day (3 per h) (USEPA, 1997a). This parameter is one of the most difficult to estimate. Therefore, site-specific conditions must be considered. Previous assessments usually assumed 1 contact per day. However, this assumption was often made with little discussion into multiple contacts per day. For the construction worker, it was assumed that the surface would be contacted more often. Therefore, a value of 12 contacts per day was selected. For the general industrial worker, fewer contacts per day were assumed, a value of 3 contacts per day was selected. The construction and industrial worker's day was assumed to be $8 \mathrm{~h}$.

6. Fraction of Dust Transferred from Surface to Skin. The fraction of dust transferred from surface to the skin is the percentage of dust that has come in contact with the skin expected to remain on the skin. The percentage of substance that will be transferred from a contaminated surface to the skin ranges from 0 to $100 \%$ (USEPA, 1997a). It is recommended that experimental values or relevant values from the literature be used if available. This value can vary widely. For the construction/ demolition and industrial worker scenarios, values of $10 \%$ were chosen.

7. Fraction of Dust Transferred from Skin to Mouth. The fraction of the dust transferred from skin to mouth is that percentage of the dust that will be transferred into the mouth from the fraction of the dermal area that contacts the mouth. This fraction assumes that not all of the dust on the dermal surface that could contact the mouth will be transferred into the mouth. The fraction of dust transferred from skin to mouth is similar to the fraction of dust transferred from surface to skin in that it can vary widely and there is little published on the appropriate choice of values. This value can also vary from 0 to $100 \%$ because it is a fraction. To be conservative, it was assumed that a higher percentage of dust would be transferred from the hands to the mouth of a construction worker as opposed to a general industrial worker. These values were assumed as 50 and $30 \%$ respectively (Schneider and Susie, 1993).

8. Hand to Mouth Events. Hand to mouth events is a measure of the number of times a person 
would bring their hand or another contaminated part of their upper extremities to their mouth. This value should be determined based upon site-specific criteria. It was assumed that the number of hand to mouth events may vary from 0 to 24 times per day similar to the contact frequency with the surface (events per day) (USEPA, 1997a). For the construction/ demolition and general industrial workers, the same number of hand to mouth events were assumed. This value was 3 per day.

9. Inhalation Rate. Inhalation rate is a measure of the amount of air a person inhales each day. The USEPA recommends several adult inhalation rates depending on activity level. The inhalation rates varied according to a normal distribution recommended by the USEPA Exposure Factors Handbook (USEPA, 1997b) around a mean construction value of $15 \mathrm{~m}^{3}$ per day, standard deviation of $6 \mathrm{~m}^{3}$ per day. For industrial workers, the mean inhalation rate was $12 \mathrm{~m}^{3}$ per day with a standard deviation of $5 \mathrm{~m}^{3}$ per day. USEPA (USEPA 1997b) values were given in units of cubic meters per hour; this value was converted to units of cubic meters per day by assuming an 8-h per day workday and simply multiplying the values by $8 \mathrm{~h}$ per day. For the industrial worker scenario, a range for moderate activity level was used. Examples of moderate activities include climbing stairs and digging. The industrial worker defined in this methodology would not be expected to conduct activities that were more than moderately strenuous. In fact, most activities would be considered light (e.g. walking). For the construction worker, a range for short-term exposure and heavy activity level was used. Examples of heavy activities include climbing stairs with heavy loads and chopping. The construction/demolition worker defined in this methodology would be expected to conduct activities comparable to the examples. All values were selected from Table 5-23 from the Exposure Factors Handbook (USEPA 1997b). To be conservative, a value of $20 \mathrm{~m}^{3}$ per day was selected for the construction/demolition worker and a value of $15 \mathrm{~m}^{3}$ per day was selected for the general industrial worker.

10. Resuspension Factor. The resuspension factor is a measure of the amount of dust expected to resuspend into the air after a disturbance of a surface covered with contaminated dust. Sansone (1987) describes many studies conducted in which concentration on surfaces and in air was measured during various activities. Concentration levels were then related to determine a resuspension factor. The range of values given in the studies spans six orders of magnitude $\left(10^{-2}-10^{-8}\right)$. For the construction scenario, a range was chosen that represented some of the more strenuous and/or dust producing activities in the studies. This range was $1 \mathrm{E}-05$ to $2 \mathrm{E}-04 \mathrm{~m}^{-1}$. For the industrial scenario, values consistent with lighter activities like walking were chosen (Sansone, 1987). This range varied between $1 \mathrm{E}-08$ to $1 \mathrm{E}-07$ $\mathrm{m}^{-1}$. The discrete values selected were $1 \mathrm{E}-04$ $\mathrm{m}^{-1}$ for the construction worker scenario and $5 \mathrm{E}-08 \mathrm{~m}^{-1}$ for the general industrial worker scenario.

11. Dermal Absorption Efficiency. The dermal absorption efficiency is a constant that indicates the relative efficiency of dermal absorption into the skin from a particular substance. Recommended values of 0.01 for inorganics and 0.1 for organics were used. However, the dermal absorption factor is a compound specific value; therefore, if compound specific information is available, it should be used in place of these default values or ranges. The range of possible values used for the wipe surface screening value calculations for explosives was between 0.01 and 0.1 . The Region IX PRG Toxicity Tables web site lists the exact values per substance (http:// www.epa.gov/Region9/waste/sfund/prg/ index.htm).

12. Exposure Frequency and Duration. Exposure frequency is site-specific and defined as a measure of the expected number of days per year that a person is exposed (USEPA, 1997b). Exposure duration is the expected number of years a person will most likely be exposed. For the construction worker scenario, the exposure duration and frequency are site-spe- 
cific. For the industrial worker scenario, the exposure duration is the average number of years a worker is expected to stay at one workplace. For the non-cancer evaluation, averaging time is equal to the exposure duration. The exposure frequency and duration can vary between 0 and 365 days per year and 0 to 70 years, respectively. For the construction worker scenario, USEPA default values were used for exposure frequency and exposure duration. These values were was 250 days per year over 1.0 year (USEPA, 1997b). For the general industrial worker scenario, exposure frequency was 21 days per year and exposure duration was assumed 25 years.

13. Body Weight. Body weight refers to a persons weight in kilograms and is typically expressed as a normal distribution of values for males and females. This value varies based upon a normal distribution around the recommended mean value of $71.8 \mathrm{~kg}$ for men, ages $18-75$ years and a standard deviation of $14.6 \mathrm{~kg}$ (USEPA, 1997b). For these calculations, the mean value of male body weight, $71.8 \mathrm{~kg}$, was selected as the discrete value for both exposure scenarios.

14. Averaging Time. Averaging time is the value used to average exposures over a person's average exposure duration (non-cancer) or lifetime (cancer). For the non-cancer evaluation, averaging time is equal to the exposure duration. This value can vary from 0 to 70 years. For the construction worker, an averaging time of 0.5 years was selected. A value of 25 years was selected for the general industrial worker.

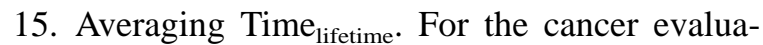
tion, averaging time is equal to an average lifespan, as defined by the USEPA, of 70 years (USEPA, 1997b). This value does not vary.

Table 2 outlines the exact parameter values chosen for the Construction and Industrial Worker.

\subsection{General risk equations}

Screening levels are established by estimating the exposure needed to achieve some agreed upon, acceptable level of risk. The general form of the risk estimation equations is given in Eq. (1), where the risk from the chemical intake is added across all the evaluated pathways. The word 'risk' in this equation should be substituted with the word 'hazard' for the non-carcinogenic evaluation. The equations in the following sections are the standard risk equations from the USEPA Risk Assessment Guidance for Superfund (RAGS) that were used as a starting point in the development of the more site-specific risk calculations (USEPA, 1989). Table 2 outlines the variable values. The specific methodology for analyzing individual carcinogenic risks and non-carcinogenic hazards is shown below.

$$
\begin{aligned}
\text { Total Risk }= & \text { Risk }_{\text {dermal }}+\text { Risk }_{\text {ingestion }} \\
& + \text { Risk }_{\text {inhalation }}
\end{aligned}
$$

Carcinogenic risks are calculated using the assumption that carcinogenesis is a non-threshold effect (i.e. there is not a 'no risk' level of exposure). The final calculated risk is the estimated increase to an individual's lifetime background risk for cancer. Eq. (2) is used to calculate the carcinogenic risk:

Risk $_{\text {carcinogenic, } p}=C S F_{p} \times L A D I_{p}$

where:

$\mathrm{CSF}_{p}$ : carcinogenic slope factor for exposure pathway $p(\mathrm{mg} / \mathrm{kg} \text {-day })^{-1}$

$L A D I_{p}$ : lifetime average daily intake for exposure pathway $p$ (mg/kg-day)

The pathway-specific $C S F_{p}$ is the carcinogenic toxicity value for a particular exposure pathway. For example, an oral-based slope factor is for the ingestion pathway. The CSF is defined as 'a plausible upper-bound estimate of the probability of a response per unit intake of a chemical over a lifetime' (USEPA, 1989). Numerically it is the upper bound of the estimate of the slope of the carcinogenic dose-response curve. This value, when multiplied by the lifetime average dose resulting from a similar route, will give an upper bound estimate of the carcinogenic risk.

The pathway-specific $L A D I_{p}$ is the average daily intake received from the specific exposure pathway 
over a receptor's lifetime. The $L A D I$ is the daily intake to a receptor averaged over 70 years. Eq. (3) is used to estimate this dose. The contact rate $\left(C R_{p}\right)$ is a route specific parameter that is an estimate of the daily intake for a receptor.

$$
\begin{aligned}
L A D I_{p}= & C s \times C R_{p} \times E F \times E D /(B W \\
& \left.\times A T_{\text {lifetime }} \times 365 \text { day } / \text { year }\right)
\end{aligned}
$$

where:

$L A D I_{p}$ : lifetime average daily intake for exposure pathway $p$ ( $\mathrm{mg} / \mathrm{kg}$-day)

$C_{s}: \quad$ surface concentration $\left(\mathrm{mg} / \mathrm{m}^{2}\right)$

$C R_{p}$ : pathway specific contact rate (defined below, $\mathrm{m}^{2} / \mathrm{d}$ )

$E F: \quad$ exposure frequency (day/year)

$E D: \quad$ exposure duration (year)

$B W$ : body weight $(\mathrm{kg})$

$A T_{\text {lifetime: }}$ averaging time (year)

Non-carcinogenic effects are expressed as hazard quotients. This calculated risk is simply the ratio of the estimated intake to the acceptable intake. As a result, if this ratio (the hazard quotient, or HQ) is less than 1 , then the estimated intake by this pathway does not exceed the acceptable dose. Eq. (4) is used to calculate the non-carcinogenic hazard quotient.

Hazard Quotient (or $\mathrm{HQ})=A D I_{p} / R f D_{p}$

where:

$A D I_{p}$ : average daily intake for pathway $p(\mathrm{mg} /$ $\mathrm{kg}-\mathrm{d}$ )

$R f D_{p}: \quad$ reference dose for pathway $p(\mathrm{mg} / \mathrm{kg}-\mathrm{d})$

Hazard quotient calculations are performed using the assumption that there is a threshold dose for a chemical. This threshold dose is the maximum dose that a receptor can receive that will not result in an adverse effect. This dose is termed the reference dose $\left(R f D_{p}\right)$, and is pathway dependent.

As with the $L A D I_{p}$, the $A D I_{p}$ is an estimate of an average daily intake. However, the averaging time used for the $A D I_{p}$ is the average for chronic exposure duration, not the lifetime average. Eq. (5) is used to estimate the $A D I_{p}$.

$$
\begin{aligned}
A D I_{p}= & C s \times C R_{p} \times E F \\
& \times E D /(B W \times A T \times 365 \text { day } / \text { year })
\end{aligned}
$$

where:

$A D I_{p}$ : average daily intake for pathway $p(\mathrm{mg} /$ kg-d)

$C_{s}: \quad$ surface concentration $\left(\mathrm{mg} / \mathrm{m}^{2}\right)$

$C R_{p}$ : route specific contact rate (defined below, $\mathrm{m}^{2} / \mathrm{d}$ )

$E F: \quad$ exposure frequency (day/year)

$E D: \quad$ exposure duration (year)

$B W$ : body weight $(\mathrm{kg})$

$A T$ : $\quad$ averaging time (year) $=$ exposure duration (year)

\subsection{Dermal risk equations}

The dermal contact rate $\left(C R_{\text {derm }}\right)$ is calculated using Eq. (6), where the equation parameters are given in Table 2. Table 2 references general ranges and specific values selected for the variables in these equations. To calculate risk as a discriminate value, point estimates must be selected as is done in Table 2 and evaluated through sensitivity analysis.

$C R_{\text {derm }}=S A_{d} \times F_{d} \times E V \times F T_{-} s s \times D A F$

where:

$C R_{\text {derm }}$ : dermal contact rate $\left(\mathrm{m}^{2} / \mathrm{d}\right)$

$S A_{d}$ : dermal surface area available for absorption $\left(\mathrm{m}^{2}\right)$

$F_{d}$ : fraction of available dermal area contacted per day (unitless)

$E V: \quad$ contact frequency with surface $\left(\mathrm{d}^{-1}\right)$

$F T \_s s$ : fraction of dust transferred from surface to skin (unitless)

$D A F$ : dermal absorption efficiency (unitless)

\subsection{Ingestion risk equations}

The ingestion contact rate is calculated using Eq. (7), where parameters are defined in Table 2. This method is used by the New York Department of Environmental Health (NYDEH) and is recommended by Region III because it considers 
ingestion through the dermal contact route of exposure. Therefore it was chosen for this work. It assumes that some fraction of the contamination that transfers to the hand is ingested through hand to mouth contact.

$$
\begin{aligned}
C R_{\text {ingest }}= & S A_{g} \times F_{g} \times E V \times F T_{-} s s \times F T \_f t m \\
& \times H T M E
\end{aligned}
$$

where:

$C R_{\text {ingest }}:$ ingestion contact rate $\left(\mathrm{m}^{2} / \mathrm{d}\right)$

$S A_{g}: \quad$ dermal surface area available for ingestion $\left(\mathrm{m}^{2}\right)$

$F_{g}: \quad$ fraction of available dermal area that contacts mouth (unitless)

$E V: \quad$ contact frequency with surface $\left(\mathrm{d}^{-1}\right)$

$F T \_s s$ : fraction of dust transferred from surface to skin (unitless)

$F T \_f t m$ : fraction of dust transferred from skin to mouth (unitless)

HTME: hand to mouth events (unitless)

\subsection{Inhalation risk equations}

The average inhalation contact rate $\left(C R_{\text {inhale }}\right)$ is calculated using Eq. (8) where parameters are defined in Table 2. $I R_{i}$ is the standard inhalation rate defined by the USEPA (1997b) and $K$ is the resuspension factor assumed for site-specific conditions (Sansone, 1987).

$C R_{\text {inhale }}=I R_{i} \times K$

where:
$C R_{\text {inhale }}:$ inhalation contact rate $\left(\mathrm{m}^{2} / \mathrm{d}\right)$
$I R_{\mathrm{I}}: \quad$ inhalation rate $\left(\mathrm{m}^{3} / \mathrm{d}\right)$
$K: \quad$ resuspension factor $\left(\mathrm{m}^{-1}\right)$

\subsection{Risk based wipe surface screening level equations}

The general RAGS equations were modified as described above; and by the uncertainty analysis. These equations were used to establish surface concentrations that correspond to acceptable levels of risk. Screening level equations are based on Eqs. (10) and (12), where the risk is cumulative over all pathways as shown in Eq. (1). For clarity, these are presented again below. The value estimated by Eq. (10) is for carcinogenic risks $\left(\right.$ Risk $\left._{\text {carcinogenic }}\right)$, and the value estimated by Eq. (12) is for non-carcinogenic hazards. In order to establish appropriate environmental screening levels an a priori level of acceptable risk must be established.

The USEPA uses a carcinogenic risk level of $1 \times 10^{-6}$ as a point of departure to establish many of its environmental screening levels. However, in many cases USEPA believes that risks from environmental carcinogens between $1 \times 10^{-4}$ and $1 \times 10^{-6}$ may be acceptable. Although constrained by feasibility issues, OSHA has used values near $1 \times 10^{-3}$ to establish many of its recent permissible exposure limits (PELs) (cf OSHA, 1987, 1997). For this method, a target risk of $1 \times 10^{-6}$ was used to establish acceptable surface concentrations based on carcinogenic effects.

For non-carcinogenic risks, the USEPA has generally used a target hazard quotient (THQ) of 1; although in cases of chemicals that may have a common target and/or mode of action, values below 1 are used to account when multiple chemicals are present. The target non-carcinogenic risk in this report was a hazard quotient of 1 , which is consistent with the USEPAs previously established environmental screening levels (USEPA, 1998, 1999).

The acceptable surface concentration is determined for each risk type (carcinogenic and noncarcinogenic) for each chemical. These levels are found by determining the surface concentration that equates to each target risk. In order to select the most conservative value, the lower of the two surface concentrations is reported. The equations used in these calculations follow. The acceptable surface concentrations based on carcinogenic effects are calculated using Eq. (10) and the variables in Table 2. This equation is derived from Eq. (9), where the surface concentration has been algebraically factored out of the equation. For chemicals that are not considered carcinogens, an acceptable surface concentration was not determined for this endpoint. To calculate wipe sample screening levels in units consistant with the sampling method, a conversion factor $(C F)$ must be 
applied to Eq. (9). Eq. (10) applies a factor of 10 to the computed surface concentration in $\mathrm{mg} / \mathrm{m}^{2}$ to obtain $\mu \mathrm{g} / 100 \mathrm{~cm}^{2}$.

$$
\begin{aligned}
T R= & e C_{\mathrm{s}}\left[\left(C R_{\text {dermal }} \times C S F_{\text {derm }}\right)+\left(C R_{\text {ingest }}\right.\right. \\
& \left.\times C S F_{\text {ingest }}\right)+\left(C R_{\text {inhale }}\right. \\
& \left.\left.\left.\times C S F_{\text {inhale }}\right)\right][E F \times E D]\right\} /(B W \\
& \left.\times A T_{\text {lifetime }} \times 365 \mathrm{~d} / \mathrm{yr}\right)
\end{aligned}
$$

where:

TR: $\quad$ target risk $\left(1 \times 10^{-6}\right)$

$C_{s}: \quad$ surface concentration $\left(\mathrm{mg} / \mathrm{m}^{2}\right)$

$C R_{\text {dermal }}:$ dermal contact rate $\left(\mathrm{m}^{2} / \mathrm{d}\right)$

$C S F_{\text {derm }}$ : dermal cancer slope factor $((\mathrm{mg} / \mathrm{kg}-$

$$
\text { d) }{ }^{-1} \text { ) }
$$

$C R_{\text {ingest }}:$ ingestion contact rate $\left(\mathrm{m}^{2} / \mathrm{d}\right)$

$C S F_{\text {ingest }}$ : ingestion cancer slope factor $((\mathrm{mg} / \mathrm{kg}$ -

$$
\text { d) }{ }^{-1} \text { ) }
$$

$C R_{\text {inhale }}$ : inhalation contact rate $\left(\mathrm{m}^{2} / \mathrm{d}\right)$

$C S F_{\text {inhale }}$ inhalation cancer slope factor $((\mathrm{mg} /$

$$
\mathrm{kg}-\mathrm{d})^{-1} \text { ) }
$$

$E F: \quad$ exposure frequency (d/year)

$E D: \quad$ exposure duration (year)

$B W$ : body weight $(\mathrm{kg})$

$A T_{\text {lifetime }}$ : carcinogenic averaging time (year)

$$
\begin{aligned}
C_{s}= & \left(T R \times\left(B W \times A T_{\text {lifetime }} \times 365 \mathrm{~d} / \mathrm{yr}\right)\right. \\
& \times C F) / \mathrm{e}\left[\left(C R_{\text {dermal }} \times C S F_{\text {derm }}\right)\right. \\
& +\left(C R_{\text {ingest }} \times C S F_{\text {ingest }}\right)+\left(C R_{\text {inhale }}\right. \\
& \left.\left.\left.\times C S F_{\text {inhale }}\right)\right] \times[E F \times E D]\right\}
\end{aligned}
$$

where:

$\mathrm{C}_{s}$ : $\quad$ surface concentration $\left(\mu \mathrm{g} / 100 \mathrm{~cm}^{2}\right)$

$C F$ : conversion factor $\left(10 \mu \mathrm{g} / 100 \mathrm{~cm}^{2}\right.$ per $\mathrm{mg} / \mathrm{m}^{2}$ )

The acceptable surface concentrations based on non-carcinogenic effects are calculated using Eq. (12) and the variables in Table 2. This equation is derived from Eq. (11), where the surface concentration has been algebraically factored out of the equation. For the chemicals that are considered carcinogens, an acceptable surface concentration was not determined for this endpoint. To calculate wipe sample screening levels in units consistant with the sampling method, a conversion factor (CF) must be applied to Eq. (11). Eq. (12) applies a factor of 10 to the computed surface concentra- tion in $\mathrm{mg} / \mathrm{m}^{2}$ to obtain $\mu \mathrm{g} / 100 \mathrm{~cm}^{2}$.

$$
\begin{aligned}
T H Q= & {\left[C_{s} \times C R_{\text {dermal }} \times E F \times E D /(B W\right.} \\
& \times A T \times 365 \mathrm{~d} / \text { year })] / R f D_{\text {derm }} \\
& +\left[C_{s} \times C R_{\text {ingest }} \times E F \times E D /(B W\right. \\
& \times A T \times 365 \mathrm{~d} / \text { year })] / R f D_{\text {ingest }} \\
& +\left[C_{s} \times C R_{\text {inhale }} \times E F \times E D /(B W\right. \\
& \times A T \times 365 \mathrm{~d} / \text { year })] / R f D_{\text {inhale }}
\end{aligned}
$$

where:

$T H Q$ : target hazard quotient (1)

$C_{s}: \quad$ surface concentration $\left(\mathrm{mg} / \mathrm{m}^{2}\right)$

$C R_{\text {dermal }}:$ dermal contact rate $\left(\mathrm{m}^{2} / \mathrm{d}\right)$

$R f D_{\text {derm }}$ : dermal reference dose $(\mathrm{mg} / \mathrm{kg}-\mathrm{d})$

$C R_{\text {ingest }}$ : ingestion contact rate $\left(\mathrm{m}^{2} / \mathrm{d}\right)$

$R f D_{\text {ingest }}$ : ingestion reference $(\mathrm{mg} / \mathrm{kg}-\mathrm{d})$

$C R_{\text {inhale }}$ : inhalation contact rate $\left(\mathrm{m}^{2} / \mathrm{d}\right)$

$R f D_{\text {inhale }}$ : inhalation reference dose $(\mathrm{mg} / \mathrm{kg}-\mathrm{d})$

$E F: \quad$ exposure frequency (d/year)

$E D: \quad$ exposure duration (year)

$B W: \quad$ body weight $(\mathrm{kg})$

$A T$ : averaging time (year)

$$
\begin{aligned}
C_{s}= & \left(\frac{T H Q}{\left[\left(\frac{C R_{\text {dermal }}}{R f D_{\text {dermal }}}\right)+\left(\frac{C R_{\text {dermal }}}{R f D_{\text {ingest }}}\right)+\left(\frac{C R_{\text {inhale }}}{R f D_{\text {inhale }}}\right)\right]}\right) \\
& \times\left(\frac{B W \times A T \times 365 \mathrm{~d} / \text { year }}{E F \times E D}\right) \times C
\end{aligned}
$$

where:

$C_{s}$ : $\quad$ surface concentration $\left(\mu \mathrm{g} / 100 \mathrm{~cm}^{2}\right)$

$C F$ : conversion factor $\left(10 \mu \mathrm{g} / 100 \mathrm{~cm}^{2}\right.$ per $\mathrm{mg} / \mathrm{m}^{2}$ )

\subsection{Monte Carlo simulation and uncertainty analysis}

Uncertainty refers to a lack of knowledge, which in theory can be reduced through further data collection. In reality, the further collection of data is often constrained by time, cost, and technological impracticalities (Aurelius and Sassaman, 1998). Potential sources of uncertainty can be divided into two broad categories: uncertainty associated with assigning values to parameters in a mathematical model (parameter uncertainties) 
and uncertainties associated with the mathematical model form (model uncertainties). Conservative assumptions were made in parameter values to ensure the safety of individuals exposed at the site. Additionally, more research is necessary to determine appropriate values for the some of the parameters used in this method. These are primarily: resuspension factor, hand to mouth events, fraction of dust transferred from skin to mouth, and contact frequency with the surface. Model uncertainty was not addressed.

Two methods of risk assessment were conducted for the site. Initially, a deterministic risk assessment was conducted producing a single-point estimate of wipe surface screening level for each of the three explosives. The deterministic approach is the currently recognized approach for quantifying risks to human health. However, in order to assess the full range of possibilities, probabilistic statistical analyses were also completed. The most frequently used and perhaps best understood of the tools used to perform this statistical analysis is called Monte Carlo analysis. Monte Carlo analyses were completed for the screening levels using the Crystal Ball ${ }^{\circledR}$ software package. Probabilistic statistical techniques allow risk estimation (screening level estimation) to incorporate most of the potential exposure and dose scenarios rather than those associated with upper-end, conservative assumptions only. Monte Carlo simulation is a statistical technique by which a risk equation is solved numerous times (10000 for this site). The inputs to the risk equation (screening level), rather than conservative point values, are some combination of point values and distribution functions that more clearly define the variability and/or uncertainty associated with each variable. Table 3 outlines the variable point values and distribution functions selected for the Monte Carlo simulation and sensitivity analysis. Each calculated screening level has an associated likelihood of occurrence. The multiple results, when plotted graphically, represent a cumulative frequency that is useful in understanding the probability of hypothetical outcomes (uncertainty). Fig. 1 graphically displays the lognormal distribution of screening levels generated by the Monte Carlo simulation for this site.
Fig. 2 depicts the key variables in the screening level risk calculations by rank correlation.

A probabilistic risk assessment is a valuable tool for quantifying uncertainty because:

- The risk equation is solved numerous times to generate a range of possible answers;

- Each calculated risk value (screening level) has an associated probability of occurrence; and

- The output of the analysis reflects the full distribution of the potential risk, not just the high-end, single-point estimate.

The summary wipe surface screening levels published in the Summary Table of this report are deterministic values that were verified using the probabilistic technique of Monte Carlo simulation.

\section{Results and discussion}

Table 1 depicts the deterministic risk assessment single-point estimate of wipe surface screening level for each explosive (HMX, RDX, Nitroglycerin) after adjustment according to the sensitivity analysis. Variables that were adjusted according to the sensitivity analysis were: resuspension factor, hand to mouth events, fraction of dust transferred from skin to mouth, and the contact frequency with the surface. The Monte Carlo simulation indicated that the screening levels for HMX, RDX and Nitroglycerin were protective based upon all potential values possible from the 10000 combinations of values. The levels calculated by this method appear to correlate well to general toxicity values. It is recommended that these levels be used as screening tools only. It is also recommended that these levels not be extrapolated to fit other exposure scenarios not contained within this report. For complete exposure assessments to toxic chemicals, it is necessary to sample all three environmental media (air, water and soil). Additionally, it must be reiterated that the dermal exposure levels calculated in this methodology are based upon ingestion toxicity values. Therefore, in the event that dermal toxicity values become available, these levels must be adjusted. Finally, conservative PPE use is warranted in all cases where unknown levels of risk exist. 
Table 3

Crystal ball@ variable probability distribution selections

\begin{tabular}{|c|c|c|c|c|c|c|c|c|c|c|}
\hline Variable & Name & Units & $\begin{array}{l}\text { EPA } \\
\text { EFH } \\
1997\end{array}$ & $\begin{array}{l}\text { EPA } \\
\text { Reg } \\
\text { III, } 1997\end{array}$ & $\begin{array}{l}\text { HBESL } \\
\text { Doc } \\
1999\end{array}$ & $\begin{array}{l}\text { Other } \\
\text { source }^{\mathrm{d}}\end{array}$ & $\begin{array}{l}\text { Value } \\
\text { other } \\
\text { source }\end{array}$ & $\begin{array}{l}\text { Value } \\
\text { selected }\end{array}$ & $\begin{array}{l}\text { Dist } \\
\text { selected }\end{array}$ & $\begin{array}{l}\text { Std. } \\
\text { dev. } \\
\text { range }\end{array}$ \\
\hline \multicolumn{11}{|l|}{ Body weight $^{\mathrm{a}}$} \\
\hline Construction & $B W \_A$ & $\mathrm{~kg}$ & 71.8 & 70 & 70 & & & 71.8 & Normal & 14.6 \\
\hline \multicolumn{11}{|l|}{ Inhalation rate ${ }^{\mathrm{b}}$} \\
\hline Industrial & IRA_child & $\mathrm{m}^{3} /$ day & 15.2 & & 20 & & 10 & 12 & Normal & 5 \\
\hline \multicolumn{11}{|l|}{ Resuspension factor } \\
\hline Industrial & $K$ Ind & None & & & & Sansone & $0.1-0.0000001$ & $5.00 \mathrm{E}-08$ & Triangular & $1 \mathrm{E}-8$ to $1 \mathrm{E}-7$ \\
\hline Construction & $K \_r$ & None & & & & Sansone & $0.1-0.0000001$ & $1.00 \mathrm{E}-04$ & Triangular & $1 \mathrm{E}-5$ to $2 \mathrm{E}-4$ \\
\hline \multicolumn{11}{|c|}{ Contact frequency with surface } \\
\hline Industrial & $C F \_s s$ & $d^{-1}$ & & $0-24$ & & & & 3 & Triangular & $0.0-24$ \\
\hline Construction & $C F \_s s$ & $\mathrm{~d}^{-1}$ & & $0-24$ & & & & 12 & Triangular & $0.0-24$ \\
\hline Industrial & $F T \_F T M$ & None & & & & & $0-1.0$ & 0.3 & Triangular & $0-1.0$ \\
\hline Construction & $F T \_F T M$ & None & & & & & $0-1.0$ & 0.5 & Triangular & $0-1.0$ \\
\hline $\begin{array}{l}\text { Dermal surface area } \\
\text { available for absorption }\end{array}$ & $S A \_D E R M$ & $\mathrm{~m}^{2}$ & & $0.01-0.02$ & & & $0.084-0.319$ & 0.198 & Uniform & $0.084-0.319$ \\
\hline $\begin{array}{l}\text { Dermal surface area } \\
\quad \text { available for ingestion }^{\mathrm{c}}\end{array}$ & $S A \_I N G$ & $\mathrm{~m}^{2}$ & & 0.02 & & & $0.084-0.319$ & 0.084 & Uniform & $0.084-0.319$ \\
\hline Hand to mouth events & HTME & None & & & & & $0-24$ & 3 & Triangular & $0.0-24$ \\
\hline $\begin{array}{l}\text { Fraction of available } \\
\text { dermal area that } \\
\text { contacts the surface }\end{array}$ & F_Derm & None & & & & Brouwer & $0.16-0.39$ & 0.25 & Triangular & $0.10-0.39$ \\
\hline
\end{tabular}

a Table 7-2 EFH.

${ }^{\mathrm{b}}$ Based on $8 \mathrm{~h}$ workday: Construction = heavy activity; Industrial=long-term, adult value.

${ }^{\mathrm{c}}$ Surface area for hands, and forearms of adult males. Range selected from mean male hand SA to mean upper extremity value.

${ }^{\mathrm{d}}$ Other source is Exposure Factors Handbook unless otherwise stated. 
Forecast: AC4

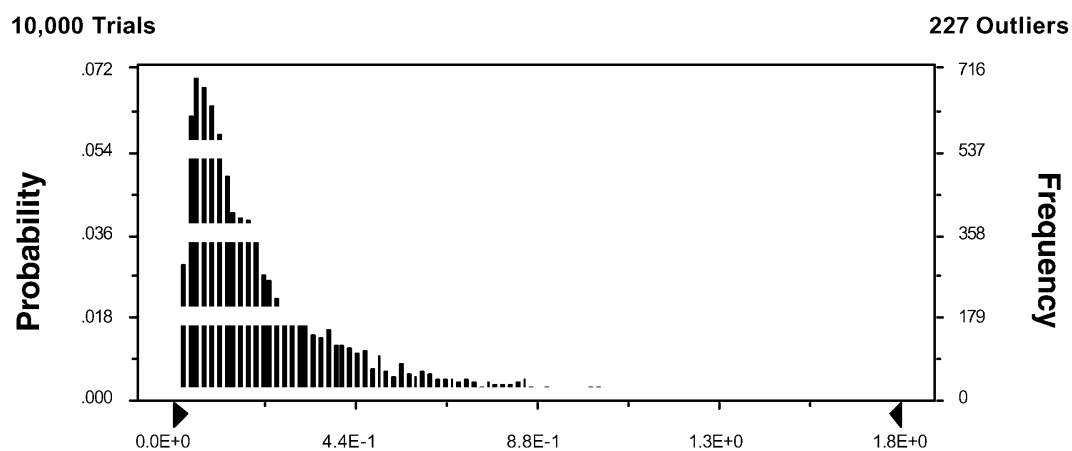

Fig. 1. This figure graphically displays the lognormal distribution of screening levels generated by the Monte Carlo simulation for this site. Fig. 1 was generated using Excel with the Crystal Ball software package. The $x$-axis is the screening level estimate in units of $\mu \mathrm{g} / 100 \mathrm{~cm}^{2}$. The left $y$-axis is the probability of each screening level estimate occurrence and the right $y$-axis denotes the frequency of each screening level estimate observed. Forecast AC4 designates the excel cell for the crystal ball forecast of the probability distribution for the construction scenario.

Monte Carlo analysis indicated that four variables were highly correlated to the screening levels and therefore more research was and will be recommended to Region IX USEPA on the appropriate discrete values that should be used in the deterministic risk assessment. The four variables are: hand to mouth events, contact frequency with the surface, fraction of dust transferred from the skin to mouth, and the dermal surface area available for ingestion. The results of this method applied to the site specific conditions for the Region IX site indicate that sensitivity analysis is a valuable tool in making resource allocation decisions as well as saving time in unnecessary research and calculation. Probabilistic analysis is valuable for the decision maker because it allows

\section{Sensitivity Chart}

Construction Scenario

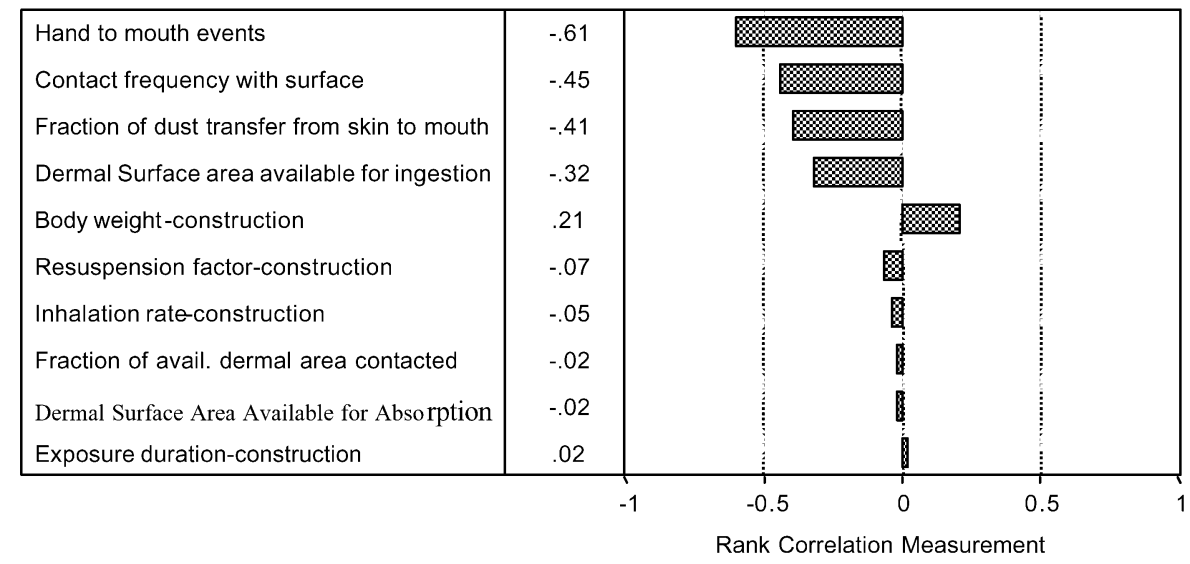

Fig. 2. This figure depicts the key variables in the screening level risk calculations by rank correlation. Fig. 2 was generated using Excel with the Crystal Ball software package. The $x$-axis is the rank correlation measurement of the variable listed on the left with the outcome variable, screening level for the construction scenario. 
simulation of many combinations of exposure scenarios and an assessment of the variability associated with the scenarios. The difficulty associated with probabilistic analysis is the selection of probability distributions for each input variable. The literature, in most cases, does not support selection of either point estimates or probability distributions for many of the variables used to determine riskbased wipe surface screening level calculations. However, once probability distributions are selected and probabilistic analysis is run, deterministic analysis becomes more accurate and meaningful to the decision maker. Therefore, it is imperative that more research occurs to describe the input variables for this risk-based method.

In the application of this method to a site, it appears as would be expected that construction levels will normally be lower than industrial levels. Additionally, it appears that the ingestion pathway drives many of the levels, which was not expected. Detection of these levels in practice through wipe sampling remains a concern of USACHPPM as regulators require these levels to determine site closure. As typical in environmental sciences, technology often is a driver to regulation. Therefore, in order to use the levels determined by this risk assessment, wipe-sampling must be capable of detecting the levels. There is also a need to correlate ingestion toxicity values to dermal toxicity values or develop dermal toxicity values where appropriate. USACHPPM would like to see more research specific to dermal contact so that some of these issues may be better addressed in the future. Many of these specific issues will be further investigated by USACHPPM with the collaboration of the USEPA Region IX and the Department of Defense Environmental liaisons. In closing, this method may be complex but after it is completed affords the risk assessor more accurate and applicable data in the place where previously none existed. We would like to see this method tested and evaluated for applicability to many types of environmental remediation and closure sites.

\section{Conclusion}

These screening levels can be used to determine if surface concentrations are acceptable under gen- eral conditions. In general, these screening levels should not be used when there is:

- A renewable source of contamination or

- Frequent surface contact that will result in significantly greater exposure/surface area assumptions.

These screening levels should be used with a specific, focused sampling plan to determine if a potential health risk exists and if surface concentrations larger than these levels will warrant further analysis. Specifically, a site-specific assessment may determine that the conditions assumed in the screening level development are in fact overconservative and that there are no unacceptable risks. On the other hand, the site-specific assessment may provide further evidence of a specific health risk that requires remedial action. The sitespecific wipe surface screening levels summarized in this report should be applied only to sites with similar exposure assumptions as developed in this method to determine risk to construction and industrial workers. This methodology may be used for other well-defined exposure scenarios only when the scenario closely mimics that presented by this method. One should also use professional judgment when applying these summary levels to interpret wipe samples at other sites. From sensitivity analysis, the screening levels summarized above are within an order of magnitude of the mean levels expected when varying uncertain exposure parameters. In some instances, a range of protective health based wipe surface screening levels may be a better method to estimate risk and protect personnel from exposures. For other situations, until additional guidance is made available, the methodology provided in this document can be used as a standard screening mechanism to assess wipe sampling data from the defined scenarios. Application of this methodology, however, must first include an evaluation of site-specific conditions to identify and reduce areas of uncertainty and/or variance from assumptions made in this method.

\section{Acknowledgments}

The authors wish to express their appreciation to all participating individuals and organizations 
for their valued input to the discussions concerning the issues addressed in this report. This report was an initiative of the Environmental Health Risk Assessment Program, US Army Center for Health Promotion and Preventive Medicine (USACHPPM), Aberdeen Proving Ground, Maryland. Special thanks go to the other USACHPPM primary contributors of this document to include Dr Coleen Weese, Occupational and Environmental Medicine Program; Dr Michael Majors, Directorate of Toxicology; Mr Thomas Runyon, Hazardous and Medical Waste Program; Mr Robert Valis, Directorate of Laboratory Sciences; $\mathrm{Mr}$ Christopher Carroll, Industrial Hygiene Field Services Program; Ms Veronique Hauschild, Deployment Environmental Surveillance Program; Mr T. Michael White and Ms Laura Peters, Environmental Health Risk Assessment Program. The authors gratefully acknowledge contributions of literature and guidance regarding wipe sampling interpretation by Dr Jeffrey Paull, United States Environmental Protection Agency (USEPA) Region IX, San Francisco, California. Appreciation is also noted for the specific support and assistance provided by Ms Bonnie Gaborek and Ms Joyce Wood as well as other USACHPPM personnel, particularly of the Environmental Health Risk Assessment Program. Reviewers of this work included staff of USACHPPM and staff of the various centers and program managers within the US Army Soldier and Biological Chemical Command (SBCCOM). For questions regarding this work, please address questions or comments regarding to Ms Lisa May at 410-436-5205 or by e-mail at lisa.may@apg.amedd.army.mil

\section{References}

Aurelius Lea, Sassaman Brian. Methods to Quantify Uncertainty in Human Health Risk Assessment. United States Air Force Armstrong Laboratory, AL-OE-BR-TR-1998-0003, February, 1998.

Brouwer Derek H. Conceptual model for assessment of dermal exposure. Occup Environ Med 1999;56(11):765-773.

New York Department of Enviromental Health (1985), PCB Reentry Guidelines, Document 1330P, July 17, 1985.

OSHA (1987), Occupational Exposure to Benzene; Final Rule. 52 FR: 34460-34578.

OSHA (1997), Occupational Exposure to Methylene Chloride; Final Rule. 62 FR: 1494-1619.

Sansone Eric B. Frederick, Maryland: Plenum Publishing, 1987:261-290.

Schneider Scott, Susie Pam. Final Report: An Investigation of Health Hazards on a New Construction Project. Occupational Health Foundation, The Center to Protect Worker's Rights. Washington, DC, April, 1993.

USEPA (1989), Risk Assessment Guidance For Superfund, Volume I, Human Health Evaluation Manual, Part A, December 1989, USEPA/540/1-89/002. http:// www.epa.gov/superfund/programs/risk/ragsa/index.htm

USEPA (1997a), Region III, Guidance for Assessing Wipe Samples, Jul 9, 1997.

USEPA (1997b), Exposure Factors Handbook, Vol. I, General Factors, August, 1997, USEPA/600/P-95/002Fa. http:// www.epa.gov/ncea/exposfac.htm

USEPA (1998), Region III, Risk-Based Concentration Table; October 1998 Update, http://www.epa.gov/reg3hwmd/ risk/riskmenu.htm.

USEPA (1999), Region IX, Preliminary Remediation Goals, http://www.epa.gov/region09/ waste/sfund/prg/index.htm 